\title{
Wear Behavior of Graphene-Platelet/Al7075 Composites Produced by Mechanical Alloying
}

Raul Pérez-Bustamante ${ }^{1}$, Fernando Pérez-Bustamante ${ }^{2}$, Juan Ramos-Cano ${ }^{2}$, Gloria Rosales-Sosa ${ }^{2}$, Hugo Arcos-Gutierrez ${ }^{3}$, Isaias Garduño-Olvera ${ }^{3}$ and R. Martínez-Sánchez ${ }^{4}$

${ }^{1}$ Corporacion Mexicana de Investigacion en Materiales, San Luis Potosi, San Luis Potosi, Mexico, ${ }^{2}$ Universidad Autonoma de Coahuila, Saltillo, Coahuila de Zaragoza, Mexico, ${ }^{3}$ CONACYT-Centro de Tecnologia Avanzada, San Luis Potosi, San Luis Potosi, Mexico, ${ }^{4}$ Centro de Investigación en Materiales Avanzados (CIMAV), Laboratorio Nacional de Nanotecnología, Chihuahua, Chihuahua, México

Graphene is an allotrope of carbon which chemical and physical properties have attracted the attention of the scientific community since its discovery [1]. The use of graphene and their applications, have been investigated in the field of polymers, ceramics, and most recently in metals [13-16]. In the particular case of metal matrix composites, a great number of investigations have been carried out in the production of aluminum composites [2, 3]. Even though, a notorious number of publications related with CNT/aluminum composites have been carried out, few literature about the production of graphene/aluminum composites is available, related with the mechanical behavior provided by graphene nanoplatelets to the matrix under an applied stress and wear conditions.

In this work, a 7075 aluminum alloy (A17075), GNPs were used in the synthesis of A17075 composites. Composites were produced by mechanical alloying (MA) in a high energy mill Spex $8000 \mathrm{M}$. The powder mass was $8.5 \mathrm{~g}$ and the ball-to-powder ratio was of 5:1. All milling runs were performed with methanol as a process control agent (PCA). Argon was used as the inert milling atmosphere. Milling time was set to $5 \mathrm{~h}$. Milled powders were cold consolidated and sintered under Ar atmosphere.

For wear evaluation a pin-on-disk system was used, specimens underwent the sliding wear tests against $\mathrm{SiC}$ abrasive papers of 220, 320 and 400 of grit under constant load. Loads of 2 and $4 \mathrm{~N}$ were transferred directly to the specimens with the use of the pin. Tests were carried out at room temperature using water as lubricant and a disc rotating speed at $2 \mathrm{~m} / \mathrm{s}$. The total sliding distance was of $960 \mathrm{~m}$ and measurements in the weight loss of the specimens were taken every $240 \mathrm{~m}$. were dried at $60^{\circ} \mathrm{C}$ for about $30 \mathrm{~s}$ and weighted in order to calculate the weight loss of the specimens in each interval of the test.

Representative TEM and HRTEM micrographs of a composite reinforced with $1.0 \mathrm{wt} \%$ of GNPs are observed in Fig 2 a,b. Micrographs reveal the presence of graphene into the aluminum matrix. A nanobeam diffraction pattern (Fig. 2a inset, NBD) of the selected zone indicated by a white circle in Fig. 2a, displays a crystalline array with a visible amorphous hallo. Fig. $3 \mathrm{~b}$ displays a magnified view of the circled zone shown in Fig. 2b. It is observed the aluminum and graphene phases, and the formation of a transition zone between them by the intercalation of atomic columns. The thickness of the graphene layers is less than 3 $\mathrm{nm}$, as it is indicated by the white square presenting atomic columns with an interplanar distance of 0.334 $\mathrm{nm}$ in accordance to the basal plane of graphite (002).

Fig. 3 c, d shows secondary electron SEM micrographs of the worn surfaces. It can be observed the morphology of the wear samples characterized by abrasive wear. Grooves in the sliding direction are observed as result of the abrasive wear as well as material smearing. Scars on the topography of the samples indicate plastic deformation, however a rougher surface is observed in the alloy (Fig. 2c), which present a softer matrix where $\mathrm{SiC}$ particles can penetrate more easily in the material surface, increasing the amount of material lost. In the other hand, the composite (Fig. 2d), present a smoother surface 
characterized by the presence of shallower scars, indicating higher wear resistance. The increase in the resistance to the abrasive wear in the composite it is due to a harder surface and increased strength due to the addition of GNPs as well as the presence of aluminum carbides. Both, GNPs and aluminum carbide, strengthen the bond with aluminum particles from the matrix reducing the amount of material loss during abrasive wear. In this regard, Kök et al [4] states that hard protruding particles are exposed after initial stages of the abrasive wear process, and whose hard nature delay the weight loss when they are in contact with the $\mathrm{SiC}$ particles because a decrease in their cutting efficiency [5].

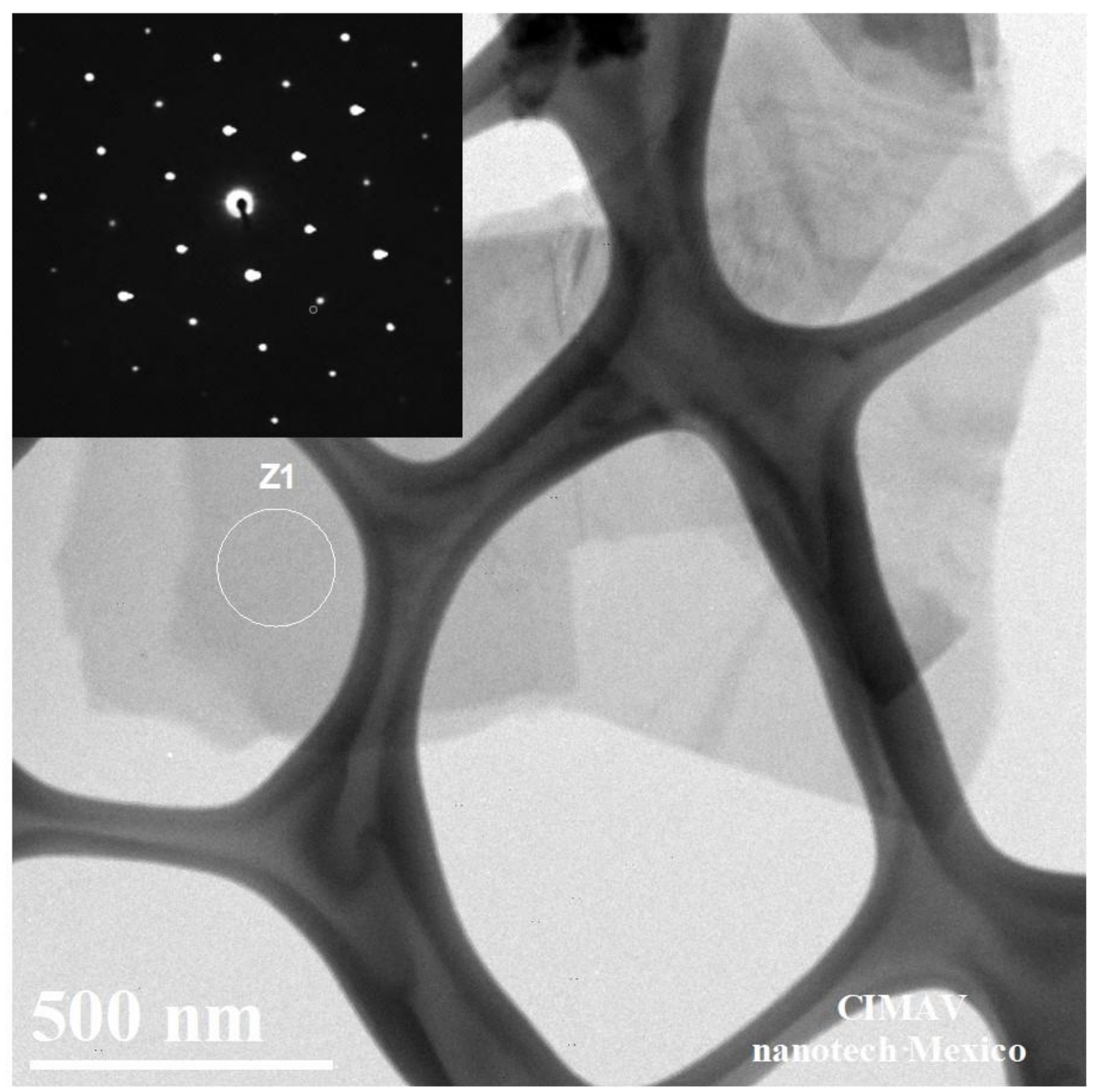

Figure 1. Bright field TEM micrographs of the reinforcement materials for the Al7075 composites 

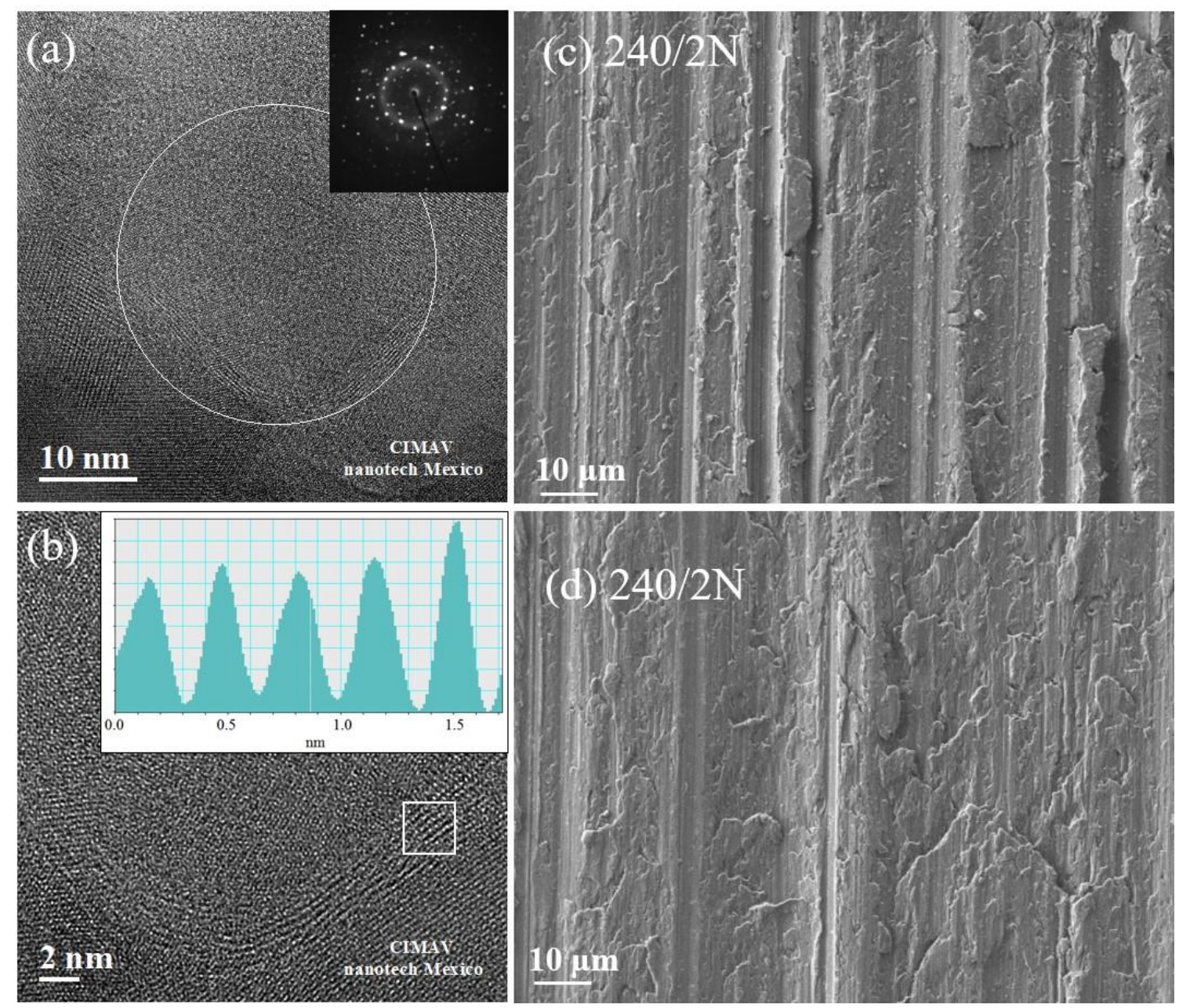

Figure 2. (a, b) Bright field TEM micrographs of the GNP/A17075 composite after sintering condition. Worn surfaces. (c) Al7075 alloy, (d) GNP/A17075 composite.

\section{References}

1. Novoselov et al, Science, 306 (2004), p. 666.

2. Bartolucci et al, Materials Science and Engineering A, 48 (528) p.7933.

3. Wang et al, New carbon materials, 34 (2019), p. 275.

4. Kök and K. Özdin, Journal of materials processing technology, 183 (2007), p. 301.

5. Pérez-Bustamante, H. Arcos-Gutierrez, I.E. Garduño-Olvera grateful with the program Cátedras CONACYT (Projects 850 and 674) for their support. 